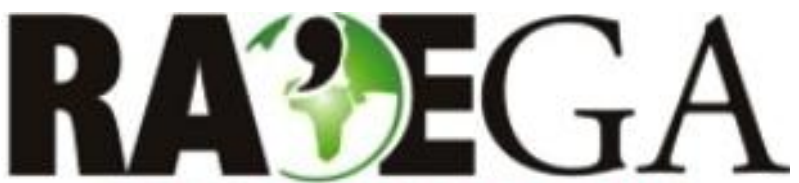

O ESPAÇO GEOGRÁFICO EM ANÁLISE

\title{
ESPACIALIZAÇÃO DA DENGUE: INDICADORES SOCIOESPACIAIS E ASPECTOS CLIMÁTICOS NO PROCESSO SAÚDE-DOENÇA
}

\section{SPATIAL DISTRIBUITION OF DENGUE: SOCIOSPATIAL INDICATORS AND CLIMATIC ASPECTS IN THE HEALTH-DISEASE PROCESS}

\author{
Rayane Brito de Almeida ${ }^{1}$, Marcela Beleza de Castro ${ }^{2}$
}

\begin{abstract}
RESUMO
Este estudo buscou identificar e analisar a formação do processo saúde-doença da dengue no município de Itacoatiara (AM) por meio da identificação do padrão socioespacial vulnerável a dengue. Tal processo abrange elementos de ordem natural e ordem social, por isso foi feito uma correlação entre a variação climática (as variáveis pluviosidade, temperatura do ar e umidade relativa) e as ocorrências de dengue, também foi mapeado a distribuição espacial da dengue, os sistemas de saneamento básico (abastecimento de água, coleta de lixo e esgoto a céu aberto) e a condição de renda da população. O presente estudo foi fundamentado na análise sistêmica de Monteiro e Mendonça na integração das variáveis climáticas e indicadores socioespaciais com as ocorrências de dengue. Os resultados identificaram relações entre a distribuição e intensidade dos condicionantes climáticos, chuva com menos de $80 \mathrm{~mm}$, temperaturas entre 24 a $35{ }^{\circ} \mathrm{C}$ e umidade entre 70 a $80 \%$ são favoráveis ao desenvolvimento do vetor. $O$ padrão socioespacial em que predominaram as ocorrências de dengue foi em unidades espaciais com problemas de saneamento básico que atingiu principalmente grupos sociais de baixo poder aquisitivo no município de Itacoatiara. Tais fatores configuraram o processo saúde-doença nas unidades espaciais de Itacoatiara como produtores de risco de dengue. A espacialização do vetor e consequentemente o desenvolvimento da doença é decorrente de um problema pré-existente, o de sistema de serviços de saneamento básico.
\end{abstract}

Palavras chave: Configuração espacial; Saneamento básico; Risco de dengue; Itacoatiara.

\section{ABSTRACT}

This study aimed to identify and analyze the formation of the dengue health-disease process in the municipality of Itacoatiara (state of Amazonas/Brazil) by identifying the socio-spatial pattern vulnerable to dengue. This process covers elements of natural order and social order, so a correlation was made between climatic variation (the variables rainfall, air temperature and relative humidity) and dengue occurrences, the spatial distribution of dengue, the systems of basic sanitation (water supply, garbage collection and open sewage) and the income condition of the population were also mapped. The present study was based on the systemic analysis of Monteiro and Mendonça in the integration of climatic variables and socio-spatial indicators with dengue occurrences. The results identified relationships between the distribution and intensity of climatic conditions, rainfall of less than 80 $\mathrm{mm}$, temperatures between 24 and $35{ }^{\circ} \mathrm{C}$ and humidity between 70 and $80 \%$ are favorable to the development of the vector. The spatial pattern in which dengue occurrences predominated was in spatial units with basic sanitation problems that affected mainly low-income social groups in the municipality of Itacoatiara. These factors shaped the health-disease process in the Itacoatiara spatial units as producers of dengue risk. The spatialization of the vector and consequently the development of the disease is due to a pre-existing problem, the system of basic sanitation services.

Keywords: Spatial configuration; Basic sanitation; Dengue risk; Itacoatiara.

\footnotetext{
${ }^{1}$ Universidade Federal do Amazonas, Manaus/AM, email:rayanebritodealmeida@gmail.com

2 Universidade Federal do Amazonas, Manaus/AM, email: marcelabelezah@gmail.com
} 


\section{ESPACIALIZAÇÃO DA DENGUE: INDICADORES SOCIOESPACIAIS E ASPECTOS CLIMÁTICOS NO PROCESSO SAÚDE-DOENÇA}

\section{INTRODUÇÃO}

A necessidade de estudos que englobassem $o$ ambiente como um dos condicionantes nos processos de saúde e doença aumentou à medida que as relações sociais com o meio ocasionaram desequilíbrios ambientais, na qual a cidade se constitui como produtora de riscos e vulnerabilidades ambientais urbanos, em particular o desenvolvimento de doenças, como aponta Costa (2015, p.74): "a existência de áreas de risco é uma realidade social, uma produção social, e não uma obra da natureza, que demanda reflexão e realização de políticas públicas socialmente justas."

Aos estudos referentes às doenças infecciosas emergentes e reemergentes, Mendonça (2004, p.157) e Pignatti (2004, p.135) apresentam o aspecto social como elemento "determinante" na distribuição das doenças. Definem-se aqui doenças emergentes aquelas cuja incidência aumentou nas duas últimas décadas numa população e as que ameaçam se expandir num futuro próximo (ROUQUAYROL, 1999, p.149); ou “aquelas causadas por microorganismos bem conhecidos que estavam sob controle, mas tornaram-se resistentes aos "inseticidas/borrifação", (a exemplo de malária, tuberculose) e estão se expandindo rapidamente em incidência ou em área geográfica (PIGNATTI, 2004, p.150; BRITO, 2007, p.40).

O vírus da dengue, por exemplo, se tornou resistente aos "inseticidas/borrifação" e é adaptativo em determinados ambiente antes não encontrado, causando epidemias da doença. Por isso a expressiva situação de epidemias ao longo dos últimos 20 anos no Brasil exigiu cada vez mais a participação de diversas áreas do conhecimento, um viés interdisciplinar na compreensão da dinâmica espacial e temporal da doença.

No que diz respeito ao aspecto climático, para Sorre (1984, p.75), Ayoade (2002, p.171) e Confalonieri et al, (2003, p.13), o clima constitui um dos principais elementos do meio a influenciar a manifestação das mais diversificadas doenças humanas, e:
A influência do clima ocorre de maneira direta e indireta, sendo tanto maléfica quanto benéfica, pois os extremos térmicos e higrométricos acentuam a debilidade do organismo para o combate às enfermidades, ocasionando maiores problemas com processos inflamatórios e, sendo assim, favorecendo a disseminação de doenças contagiosas. (SOUSA 2008, p.74).

McMichael et al. (2006, p.862), Rouquayrol e Goldbaum (1993, p.53) destacam a temperatura do ar, a umidade relativa e a precipitação pluviométrica como os aspectos do clima que mais influenciam os seres vivos no processo de transmissão de doenças, e esses elementos climáticos afetam "a capacidade de reprodução e sobrevivência de agentes patogênicos no meio ambiente e, principalmente, dos chamados vetores de agentes infecciosos, tais como os mosquitos envolvidos na transmissão da dengue". (MAGALHÃES e ZANELLA, M. E., 2013, p. 36).

Para Magalhães et al. (2013, p.36) e Mendonça (2003, p.207), a dengue se apresenta socialmente complexa, afetando seres humanos independente da sua classe social e constituindose, atualmente, dentre as mais importantes doenças transmissíveis do mundo, especialmente nos países tropicais, onde as condições ambientais, em particular as climáticas, associadas à ineficácia das políticas públicas de saúde e urbanização sem infraestrutura adequada, favorecem o desenvolvimento e dispersão de seus vetores, Aedes aegypti e Aedes albopictus.

No Brasil, foram registradas grandes epidemias de dengue, a primeira epidemia ocorreu no ano de 1998, com 507.715 casos, posteriormente, 2002 com 696.472 casos, em seguida 2008 com 638.680, com intervalo de quatro anos até a próxima epidemia. A partir de 2010 até 2013, a frequência dos casos de dengue foi consecutiva e acima dos 500 mil casos, sendo 


\section{ESPACIALIZAÇÃO DA DENGUE: INDICADORES SOCIOESPACIAIS E ASPECTOS CLIMÁTICOS NO PROCESSO SAÚDE-DOENÇA}

2013 o ano mais epidêmico, com 1.452 .489 ocorrências e 2010 com 1.011.548 ocorrências de dengue (MS, 2014).

No estado do Amazonas, os anos epidêmicos foram registrados no ano de 1998 (13.894), 2001 (19.249), 2011 (61.988) e 2013 (17.832), nos quais mais de $80 \%$ se concentraram nas grandes áreas urbanas, como em Manaus, em Itacoatiara e em Manacapuru (MS, 2014). Partindo das perspectivas aqui apontadas, o presente estudo buscou identificar e analisar a distribuição espacial e temporal dos casos de dengue a partir de indicadores socioespaciais e aspectos climáticos (pluviosidade, temperatura do ar e umidade relativa) na explicação do processo saúde-doença no município de Itacoatiara (AM). A escolha deste município para o estudo foi devido a este ser o segundo município (depois de Manaus) com maiores notificações de dengue.

\section{MATERIAIS E MÉTODOS \\ 2.1 UNIDADE ESPACIAL DE ANÁLISE}

O município de Itacoatiara (identificado na Figura 1) localizado ao leste da capital (Manaus) e margem esquerda do rio Amazonas, abrange uma área de $8.892 .038 \mathrm{~km}^{2}$, no qual $10.2412 \mathrm{~km}^{2}$ estão em perímetro urbano, dados obtidos do Instituto Brasileiro de Geografia e Estatística (IBGE, 2015). A população alcançou 98.503 habitantes, conforme a estimativa populacional de 2016 , sendo o 3 o mais populoso do estado. A taxa de urbanização cresceu 13,38\% passando de $63,62 \%$ de urbanização no município em 1991, para 77,00\% em 2010. Registrou-se que $77 \%$ da população viviam em zona urbana $(65.327$

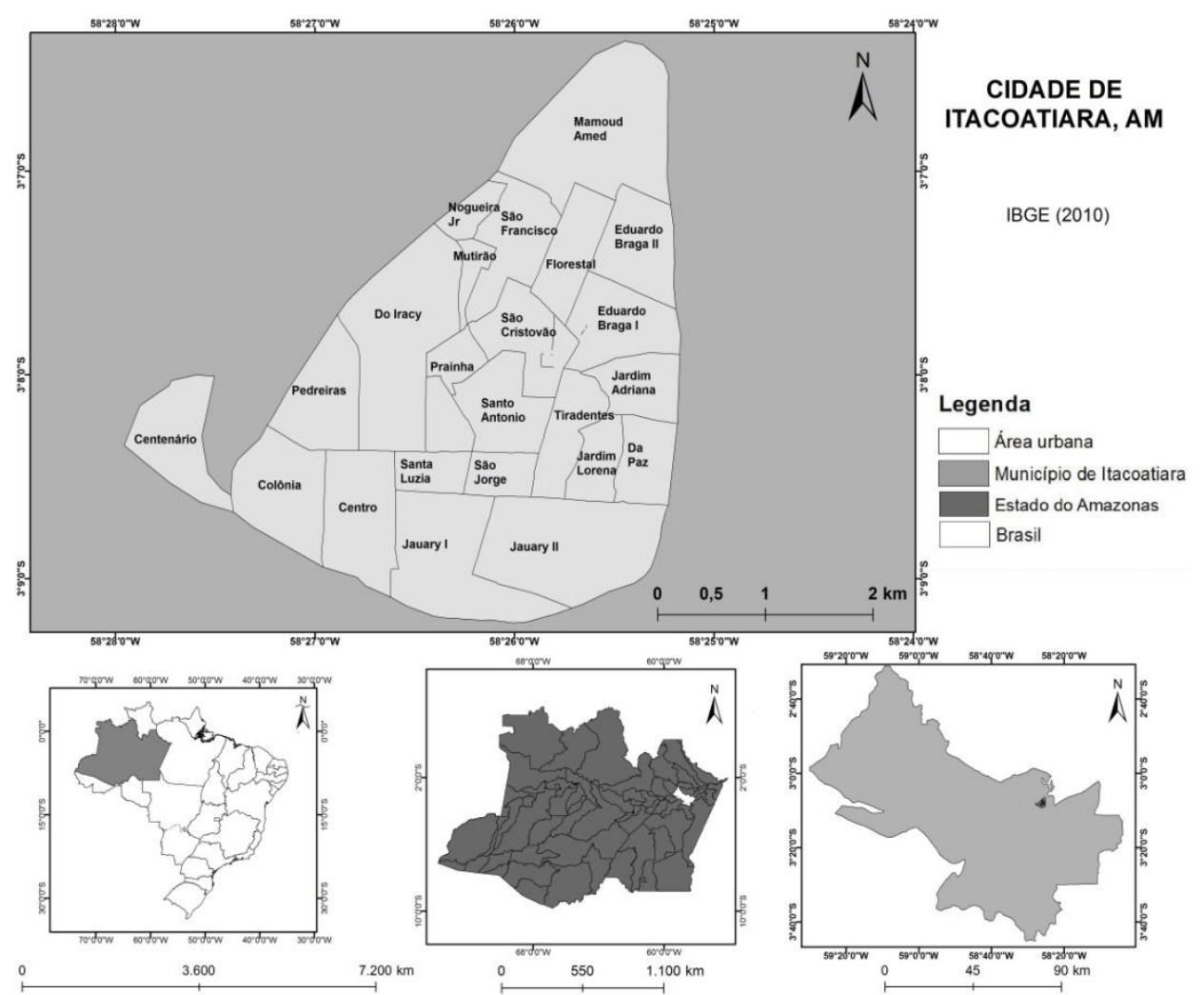

Figura 1: Unidade Espacial de Análise Itacoatiara - Amazonas. Divisão por bairros. Fonte: IBGE (2010).

Em relação ao clima do município de Itacoatiara, este é caracterizado como clima tropical, quente e úmido, apresentando temperaturas elevadas e chuva intensa. Possui chuva significativa ao longo do ano, mesmo durante o mês mais seco ainda assim tem muita 


\section{ESPACIALIZAÇÃO DA DENGUE: INDICADORES SOCIOESPACIAIS E ASPECTOS CLIMÁTICOS NO PROCESSO SAÚDE-DOENÇA}

pluviosidade. A classificação do clima é Af segundo Köppen (1901) (Figura 2). Ao longo do ano, Itacoatiara tem uma temperatura média de
$26.9{ }^{\circ} \mathrm{C}$, umidade relativa acima de $70 \%$ e pluviosidade média anual de 2261 milímetros.

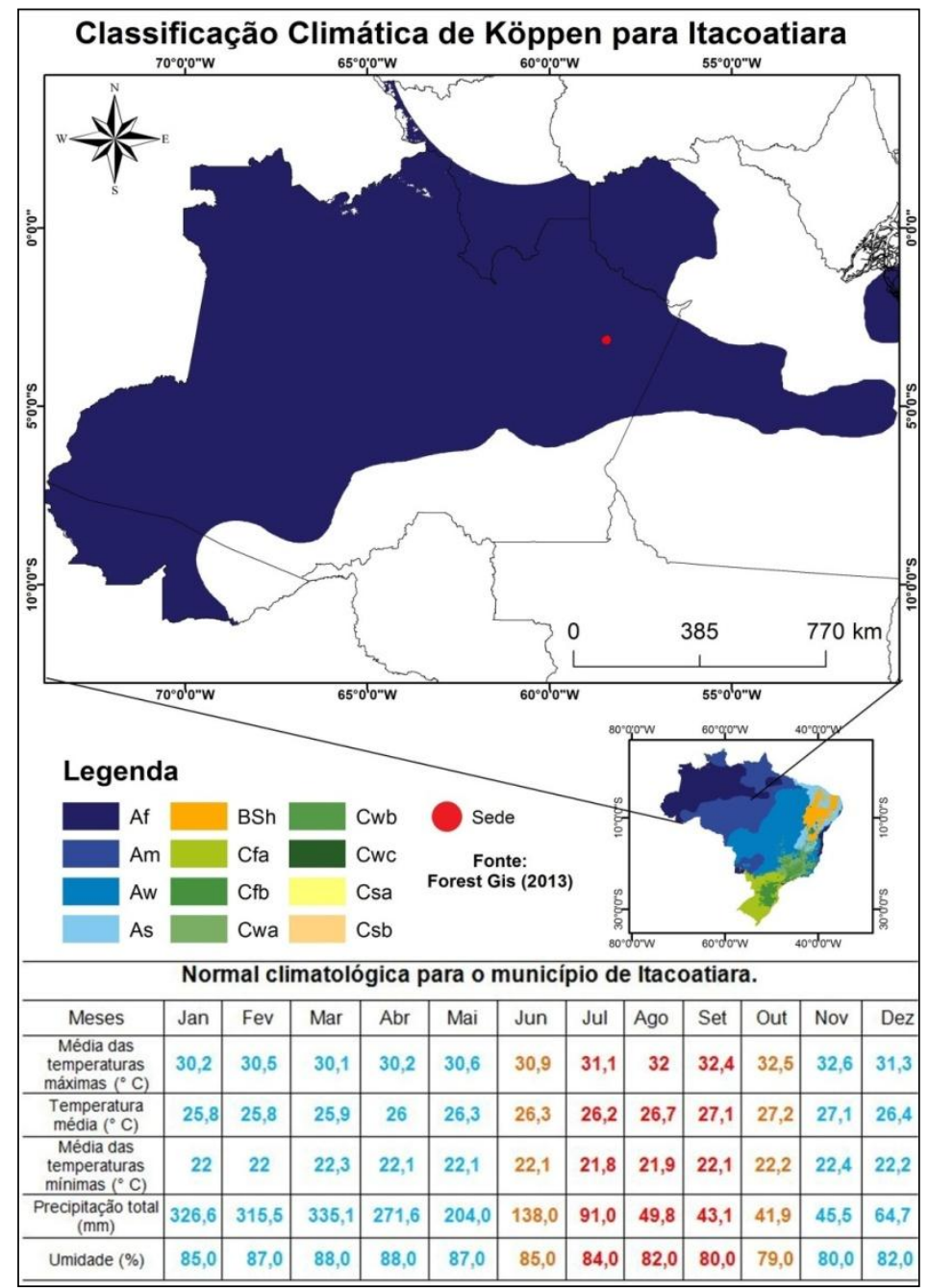

Figura 2: Clima de Itacoatiara, Af, segundo a classificação de Köppen. A tabela corresponde à normal climatológica da cidade. As cores azuis correspondem aos meses do período chuvoso, as cores vermelhas aos meses do período de estiagem (verão) e os meses alaranjados ao período de transição entre ambos. Fonte: Forest Gis (2013) e INMET (2016).

\subsection{BASES DE DADOS}

Os dados foram estruturados em casos notificados e confirmados de dengue ao longo dos anos 2001 a 2016, obtidos pela Fundação de Vigilância em Saúde (FVS) do Estado e da secretaria de saúde do próprio município.

Em relação ao aspecto espacial do município, foram obtidas informações do percentual de domicílios que possuem abastecimento de água (encanada), domicílios com abastecimento e esgoto sanitário inadequado, domicílios com coleta de lixo (serviço oficial de limpeza), população e renda per capita dos bairros pelo censo de 2010 do IBGE.

Os dados de clima utilizados foram as variáveis pluviosidade, temperatura do ar (máxima, mínima e média) e umidade relativa do ar, obtidos pelo banco histórico do INMET. O período de análise corresponde aos anos de 1998 


\section{ESPACIALIZAÇÃO DA DENGUE: INDICADORES SOCIOESPACIAIS E ASPECTOS CLIMÁTICOS NO PROCESSO SAÚDE-DOENÇA}

a 2016, a fim de correlacionar a variabilidade climática com as ocorrências de dengue, visto que o clima constitui um importante condicionante para a ecologia do vetor da dengue.

\subsection{PROCEDIMENTOS METODOLÓGICO}

TEÓRICO-

O presente trabalho foi baseado em abordagens sistêmicas, a fim de identificar o padrão socioespacial e climático das ocorrências de dengue no município:

a) Sistema Clima Urbano (S.C.U.) de Monteiro (1976, p.61), tal procedimento abrange a interação sistêmica entre a cidade e seu clima local, a particularidade climática resultante da relação do fato natural (elementos climáticos, atmosfera) com o fato social (cidade) onde o desenvolvimento e dispersão da dengue são influenciados por tal, aspecto enfatizado anteriormente e analisados em trabalhos como Paula (2005, p.117), Oliveira (2006, p.89) e Aquino Junior (2010, p.102), dentre outros.

O S.C.U. é fundamentado via embasamento cartográfico e constitui três subsistemas: termodinâmico, físico-químico ou hidrometeórico, neste estudo foi aplicado o subsistema termodinâmico, referente à temperatura e umidade do ar; e o subsistema hidrometeórico, direcionado aos impactos relacionados à pluviosidade. As variáveis temperaturas do ar, umidade e chuva no presente estudo foram analisadas em escala mensal juntamente com as notificações de dengue por meio da elaboração de gráficos.

b) Sistema Ambiental Urbano (S.A.U.): este teórico-metodológico aborda os riscos e vulnerabilidades socioambientais urbanos, problemas emanados da interação sociedade e natureza (MENDONÇA, 2001, p.124), estudo direcionado às cidades, onde os espaços urbanos se configuram nas áreas de mais intensa modificação da paisagem (herança de processos naturais e sociais). O atrelamento entre as condições-modo de vida urbana se encontra na gênese dos problemas ambientais urbanos, fato que os torna socioambientais (MENDONÇA, 2009, p.122).

Esta abordagem sistêmica compõe três subsistemas: natural, social e construído e mais subdivisões destes, cabendo a cada estudo o qual ser aplicado. Deste modo, foi elaborado um diagrama abrangendo tanto os aspectos climáticos como os socioambientais a fim de analisar a espacialização da dengue no município de Itacoatiara (Figura

4).

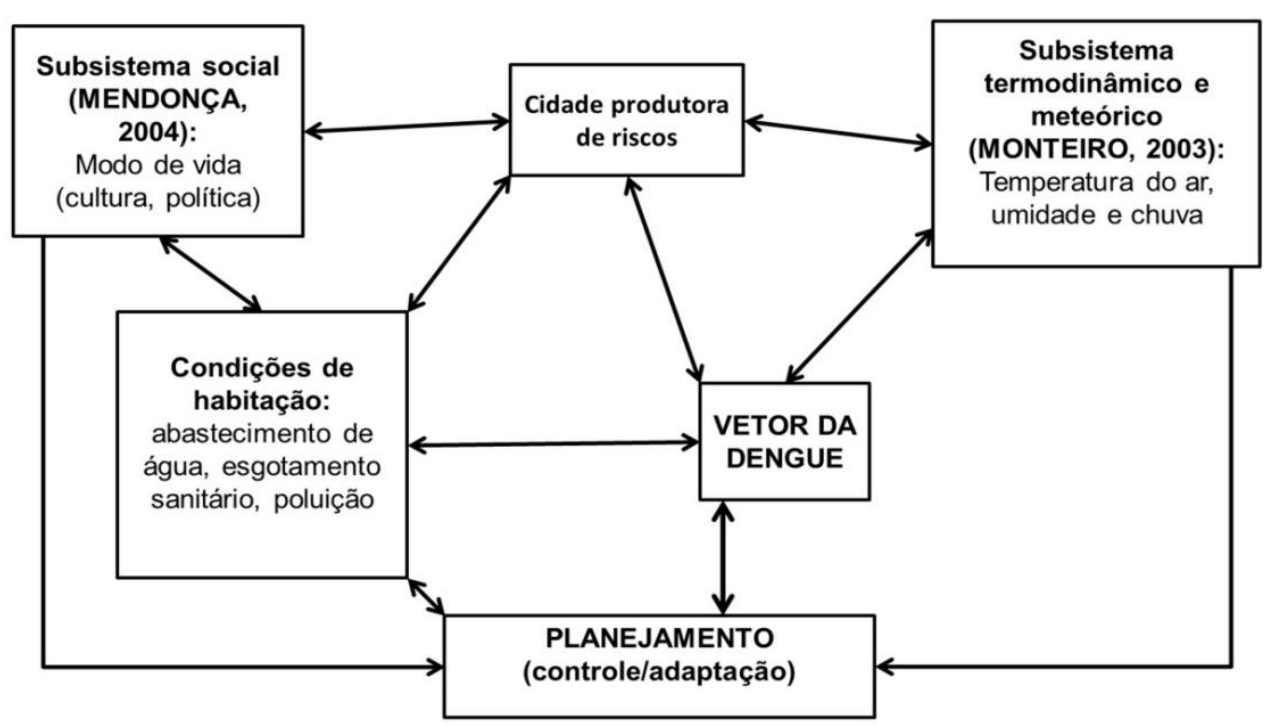

Figura 3: esquema teórico-metodológico para este estudo. Org. dos autores, 2017. 

SAÚDE-DOENÇA

\section{RESULTADOS E DISCUSSÃO}

\subsection{PARTICULARIDADES CLIMÁTICAS E A DENGUE EM ITACOATIARA}

Em relação às temperaturas do ar, representados na Figura 4 e 5 , os resultados identificaram que no período de 2001 a 2016, a temperatura máxima se manteve entre 30 a $35^{\circ} \mathrm{C}$, a temperatura média variou entre 26 a $30^{\circ} \mathrm{C}$ e a temperatura mínima entre 23 a $25^{\circ} \mathrm{C}$. A variação da umidade entre os anos de 2001 a 2008 (Figura 4) era 76 a 90\%, mas a partir do ano de 2009 até 2016 (Figura 5), a variação passou a ser entre 66 a $88 \%, 10 \%$ a menos. O período de estiagem é marcado entre os meses de julho a outubro, mas os registros de baixa umidade passaram a ser a partir de junho, evidenciando um prolongamento deste período de baixa umidade a partir de 2014. O dado de umidade relativa no mês de abril não foi registrado por falhas técnicas.

Os registros de chuva mostram que nos anos entre 2001 a 2010, as chuvas eram mais distribuídas ao longo dos anos, e a partir de 2011 (Figura 5), as chuvas passaram a ser mais concentradas. $O$ intervalo de picos de chuvas acima de $500 \mathrm{~mm}$ era a cada dois anos, a partir de 2011, as ocorrências com esse total de $\mathrm{mm}$ foram sucessivas, principalmente nos meses fevereiro e março, superando a média da cidade (315 e $335 \mathrm{~mm}$, respectivamente). O período de estiagem passou a ter intervalo de um mês com zero $\mathrm{mm}$ de chuva, como em agosto, setembro e raramente outubro (Figura 5).

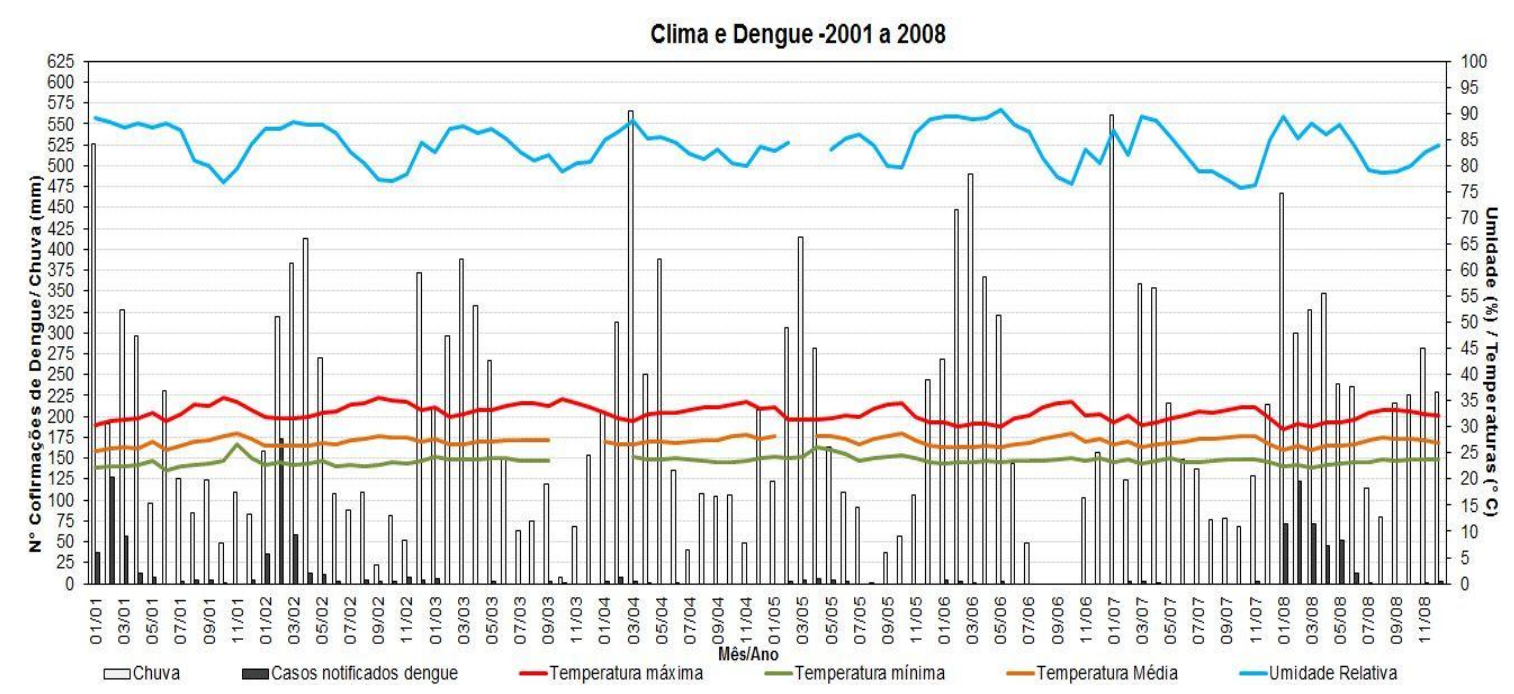

Figura 4: Correlação dos casos confirmados de dengue com as variáveis climatológicas nos anos 2001 a 2008. INMET, 2016. 


\section{ESPACIALIZAÇÃO DA DENGUE: INDICADORES SOCIOESPACIAIS E ASPECTOS CLIMÁTICOS NO PROCESSO SAÚDE-DOENÇA}

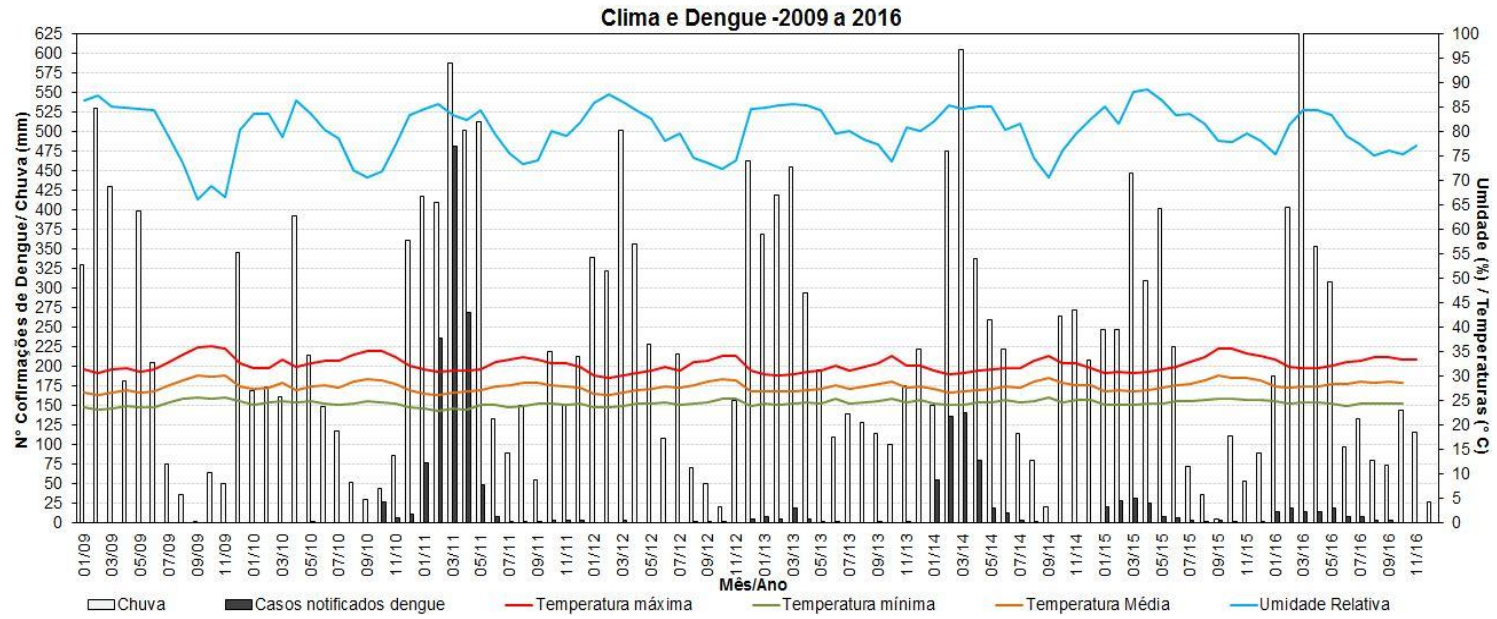

Figura 5: Correlação dos casos confirmados de dengue com as variáveis climatológicas nos anos 2009 a 2016. Fonte: INMET, 2016.

Ainda nas Figuras 4 e 5 , a dengue apresentou uma sazonalidade específica para sua ocorrência, durante os meses de janeiro a maio são registrados os maiores números de casos, de até 475 ocorrências, e volta a ter registros apenas em novembro, porém com menor proporção, 25 ocorrências. Ao longo dos meses de junho a outubro dos anos de 2003 (Figura 4) a 2009 (Figura 5), não foi registrado nenhuma ocorrência de dengue, somente nos anos de 2001, 2002 e a partir de 2010, cujos anos, foram epidêmicos para a cidade.

A partir da correlação dos elementos climáticos chuva, temperaturas e umidade correlacionadas com as notificações de dengue, foram identificadas duas situações: a primeira é que o total de $\mathrm{mm}$ de chuva tem de ser menos de $80 \mathrm{~mm}$, temperaturas entre 24 a $35^{\circ} \mathrm{C}$ e umidade entre 70 a $80 \%$ durante os meses de outubro a novembro para condicionar o desenvolvimento do vetor da dengue nos próximos meses, como dezembro a maio dos anos 2002, 2008, 2011, e nos anos consecutivos. A segunda situação é que chuvas acima de $110 \mathrm{~mm}$ ou sucessivos meses de picos de chuva, temperaturas entre 23 a $30{ }^{\circ} \mathrm{C}$ e umidade entre 60 a $70 \%$ nem acima de $80 \%$ foram inoperantes para o desenvolvimento do vetor, não havendo, portanto, registros da doença nos próximos meses como foi evidenciado no final do ano de 2001 e começo de 2002, final do ano de 2003 e começo de 2004, final de 2006 e começo de 2007, como comprovado na Figura 4.

\subsection{PADRÃO SOCIOESPACIAL VULNERÁVEL AO RISCO DE DENGUE EM ITACOATIARA}

Com base na abordagem sistêmica socioambiental, se buscou identificar na cidade de Itacoatiara, os bairros que configuraram um padrão socioespacial vulneráveis à dengue. 0 mapeamento foi referente aos casos confirmados de dengue por bairro, direcionado apenas aos anos de 2014 e 2015 por terem sido disponibilizados com a identificação de unidades espaciais (bairros) onde ocorreu a doença. O mapeamento também consistiu na espacialização dos indicadores de saneamento básico por bairro.

Na Figura 6, os casos confirmados de dengue variaram até 113, tanto no ano de 2014 como em 2015. Contudo, sua distribuição se configurou de forma desigual, sendo os bairros Jauary II e Santo Antônio com casos entre 57 a 113 no ano de 2014. No ano de 2015, apenas o bairro Jauary II permanece com números altos de casos. 

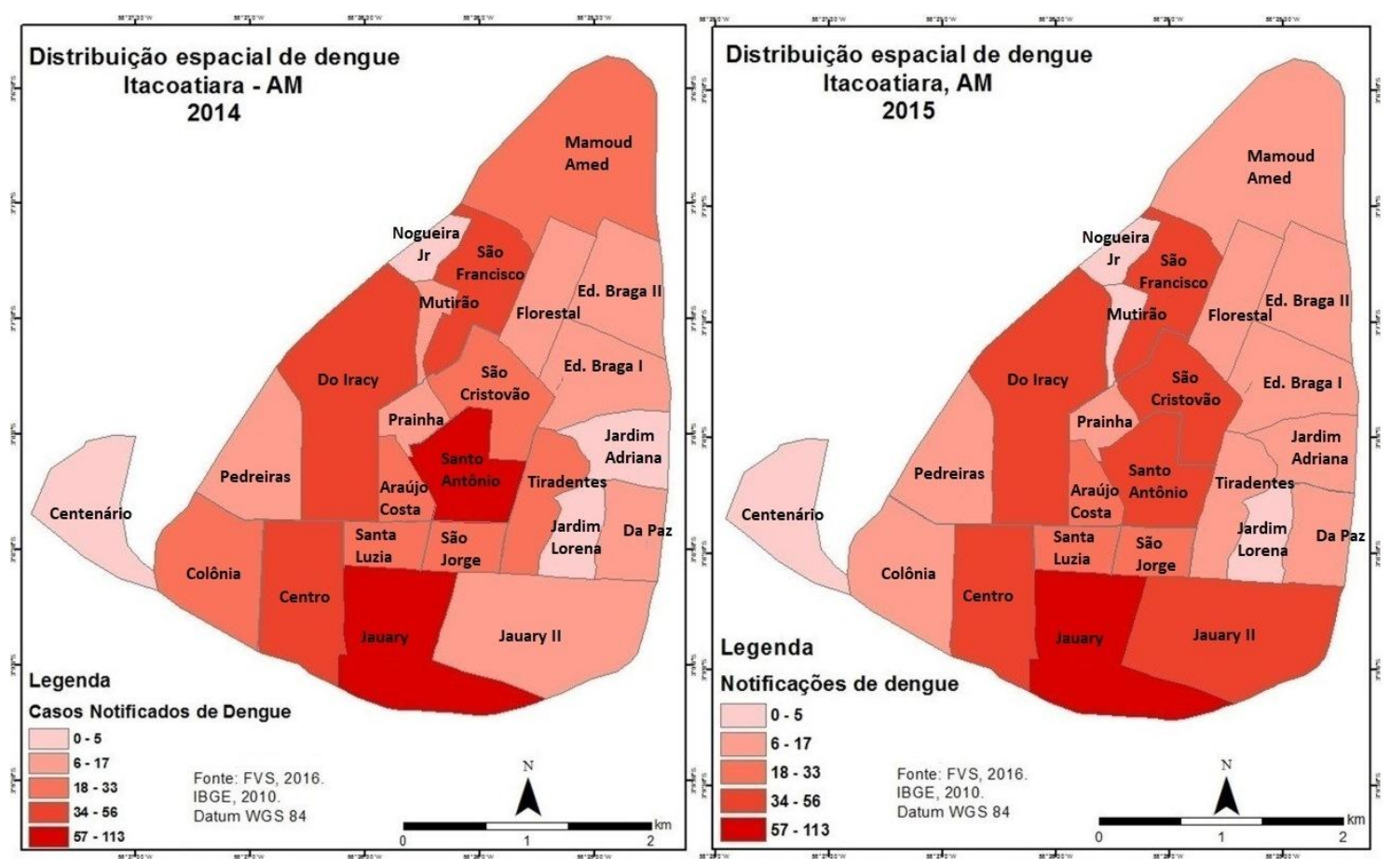

Figura 6: espacialização dos casos notificados de dengue por bairro que compõem a área urbana. Fonte: Censo do IBGE, 2010.

Posteriormente a Jauary II, os bairros que mais apresentaram casos foram Centro, Do Iracy, São Francisco, São Cristóvão e Jauary II, tanto no ano de 2014 como em 2015. A concretude dos casos se restringiu principalmente ao oeste-centro-sul da cidade como pôde ser visto na Figura 6.

Os mapas da Figura 7 se referem ao percentual de domicílios que possuem água encanada e percentual de domicílios com abastecimento de água e esgoto sanitário inadequado, segundo o censo de 2010 realizado pelo IBGE. Com base na figura, mais de $90 \%$ dos domicílios dos 24 bairros possuem água encanada, e os bairros que possuem até $100 \%$ de água encanada são os bairros Colônia (oeste-sul da cidade), Araújo Costa (centro da cidade) e Tiradentes (ao leste da cidade). Contudo, o bairro que apresentou percentual inferior aos demais foi Jauary II, ao leste da cidade. 


\section{ESPACIALIZAÇÃO DA DENGUE: INDICADORES SOCIOESPACIAIS E ASPECTOS CLIMÁTICOS NO PROCESSO SAÚDE-DOENÇA}

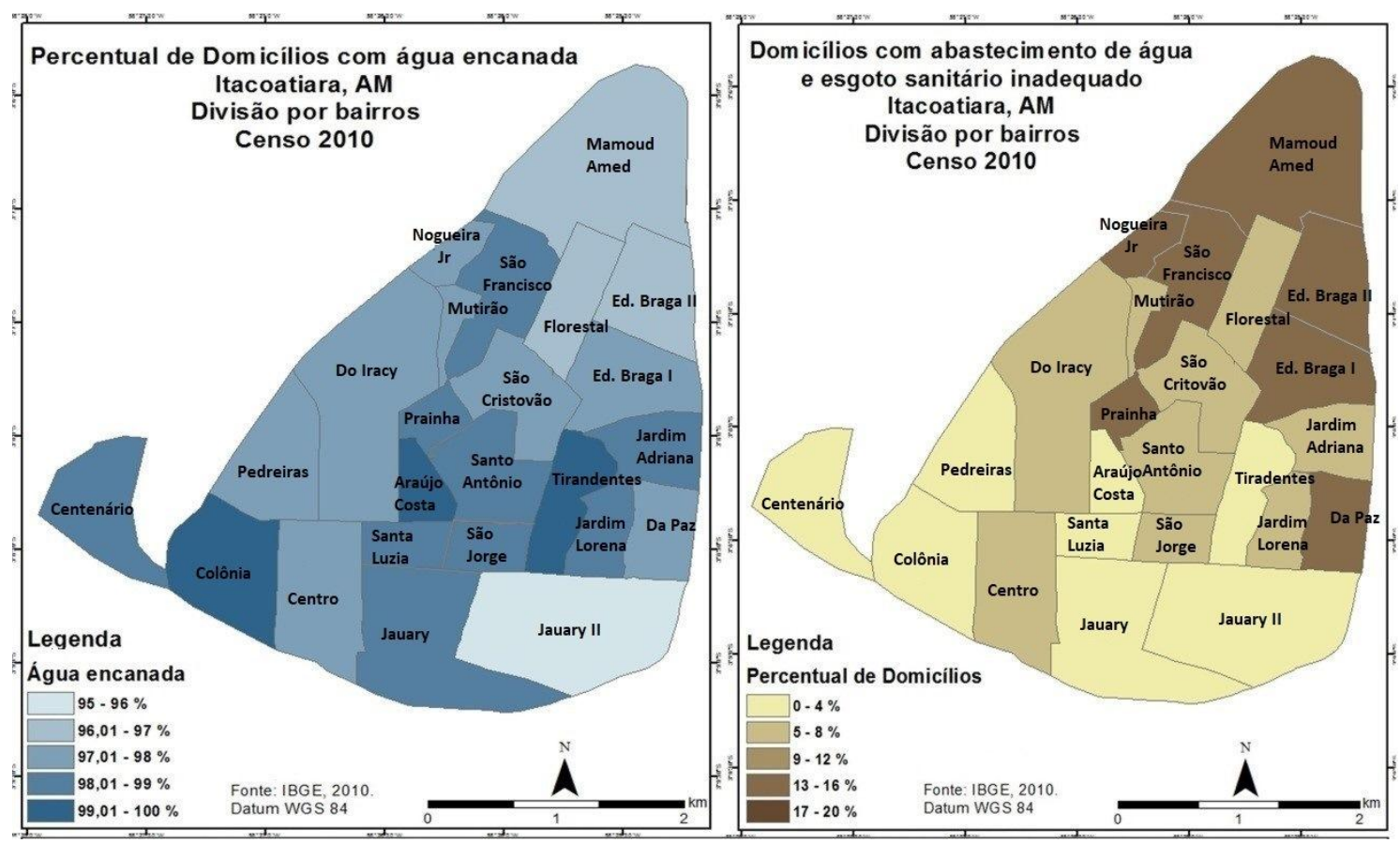

Figura 7: Mapeamento do percentual de domicílios com água encanada e abastecimento de água e esgoto sanitário inadequado conforme os bairros da cidade de Itacoatiara. Fonte: Censo do IBGE, 2010.

O termo inadequado não se refere ao "abastecimento", mas na "forma" de como a água é armazenada. Evidentemente os domicílios que não possuem água encanada procuram um meio de se abastecer, mas há o risco de a água não ser potável, bem como à exposição de vetores portadores de doenças. O ambiente domiciliar se torna propício não apenas ao desenvolvimento do vetor da dengue, mas também à propagação de outras doenças como a leptospirose, Hepatite A e diarreia, todas resultantes das formas de abastecimento de água e esgoto sanitário inadequado.

Seguido de Jauary II, os bairros Florestal, Eduardo Braga e Mamoud Amed foram os bairros que apresentaram menor percentual de domicílios com água encanada (Figura 7), assim como também apresentaram maior percentual de irregularidade no abastecimento de água e esgoto sanitário, concomitantemente, os domicílios destes bairros buscam outra maneira de abastecer água, como poços, caixas e tanques. Dos bairros citados no parágrafo acima, houve uma correlação entre o baixo percentual de água encanada, abastecimento de água e esgoto sanitário inadequado e casos confirmados de dengue (Figura 6) no bairro Mamoud Amed, até 58 casos confirmados em 2014 e 33 em 2015. O bairro Jauary também apresentou correlação no baixo percentual de domicílios com água encanada e altos casos confirmados de dengue, sendo 113 casos em 2014 e 2015. Jauary II apresentou a mesma configuração de saneamento e dengue, baixo percentual de água encanada e até 56 casos confirmados de dengue em 2015.

Bairros como São Francisco, São Cristóvão, Do Iracy, e Centro apresentaram casos de dengue inferior a Jauary e Mamoud Amed, porém significativos em correlação com o abastecimento de água e esgoto sanitário inadequado. Segundo os dados do censo do IBGE de 2010, cerca de 98 domicílios, em cada bairro citados acima, procuram outras formas de abastecimento, a exemplo de Jauary II, que possui igarapés ao leste do bairro, no entanto, ao mesmo tempo que a utilizam, há o acúmulo de lixo no entorno dos domicílios que a poluem, deixando os moradores vulneráveis à dengue e a outras doenças. 


\section{ESPACIALIZAÇÃO DA DENGUE: INDICADORES SOCIOESPACIAIS E ASPECTOS CLIMÁTICOS NO PROCESSO SAÚDE-DOENÇA}

Em relação ao mapeamento dos bairros com coleta de lixo, identificada na Figura 8 , os domicílios que apresentaram menor percentual de coleta de lixo se concentraram, principalmente, na zona norte e leste da cidade.

Os bairros com menor percentual de domicílios com coleta de lixo foram Prainha (oeste-centro da cidade), Mamoud Amed, Nogueira Junior, São Francisco (norte da cidade), Eduardo Braga I e II (norte-leste da cidade) e Da Paz

(leste).

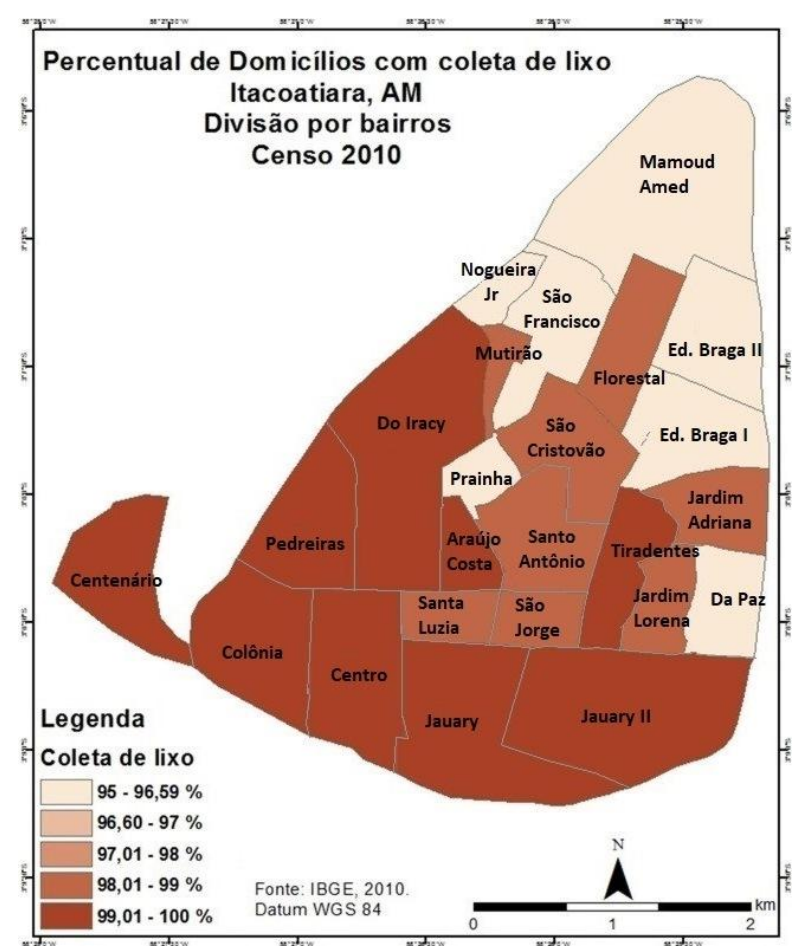

Figura 8: Mapeamento do percentual de domicílios com coleta de lixo, divisão por bairros. Fonte: Censo do IBGE, 2010.

O percentual de coleta de lixo se restringe ao serviço de limpeza e coleta da prefeitura local, onde 95 \% são coletados (apresentado na Figura 8), no entanto, $5 \%$ tem o descarte diferente, comumente tem o destino em terrenos baldios, igarapés (tipo de curso fluvial), jogados na rua ou queimados. Por exemplo, segundo o censo de 2010, o bairro Jauary possuía até 1277 domicílios do qual, 750 possuíam o benefício da coleta e 524 domicílios foram classificados como "outro tipo de coleta", o bairro Mamoud Amed possuía 775 domicílios, dos quais somente 435 domicílios tinham o lixo coletado pelo serviço de limpeza, enquanto que 440 domicílios também tinham "outro tipo de coleta", que devem ter o mesmo destino como os exemplos citados acima.
Outros bairros que a serem ressaltados são Tiradentes, 550 domicílios e 261 sem o serviço de limpeza; Santo Antônio, 975 domicílios e 193 sem o serviço de limpeza; Jauary II 519 domicílios e 182 sem o serviço de limpeza; Araújo Costa, 452 domicílios e 161 sem o serviço de limpeza e Eduardo Braga II, 380 domicílios e 136 sem o serviço de limpeza.

A diferença percentual do quanto é coletado e o quanto não é coletado equivale a mais de 2.000 domicílios sem o serviço de limpeza, segundo os dados do IBGE. A desigualdade de tal serviço tem tornado ambientes propícios ao desenvolvimento do vetor, a exemplo, Jauary, o bairro com maior número (524) de domicílios sem serviço de coleta, e foi o mesmo bairro que apresentou 


\section{ESPACIALIZAÇÃO DA DENGUE: INDICADORES SOCIOESPACIAIS E ASPECTOS CLIMÁTICOS NO PROCESSO SAÚDE-DOENÇA}

maior número de casos confirmados de dengue (113) em 2014 e 2015 (Figura 6). Os impactos de acúmulo de lixo condicionam não só o desenvolvimento do vetor da dengue, mas a poluição do solo e recursos hídricos. Diferente do percentual dos bairros Santa Luzia e São Jorge, por exemplo, que possuem 470 e 445 domicílios, respectivamente, e ambos tinham o lixo coletado $100 \%$, estes bairros tiveram até seis casos confirmados de dengue em 2014 e 2015 (Figura $6)$.

Mesmo com um número significativo de domicílios sem coleta de lixo, Itacoatiara apresenta os bairros acima de $90 \%$, outros bairros com $100 \%$ da população com acesso a esse tipo de serviço, que é essencial para o controle da dengue, pois a ineficácia da coleta de lixo gera acúmulo de resíduos a céu aberto, que servem como criadouro para o desenvolvimento, reprodução e evolução do vetor da dengue, como exemplos de bairros aqui analisados.

Estudos como de Aquino (2010) identificaram uma forte relação entre as unidades espaciais com os fatores densidade demográfica e renda com as ocorrências de dengue, para tanto, foi elaborado um mapa do total de habitantes e renda per capita (em R\$) para cada bairro, a fim de identificar uma correlação com a dengue, como é evidenciado nos mapas da Figura 9.

O mapa populacional de Itacoatiara identificou os bairros Jauary, São Cristóvão e São Francisco como mais populosos, entre 4.528 e 5.659 habitantes, e Do Iracy, Santo Antônio e Mamoud Amed como os segundos mais populosos, entre 3.3396 e 4.527 habitantes. Os bairros menos populosos são Jardim Lorena, Jardim Adriana e Centenário (Figura 9).

Em relação à renda per capita, que é a razão entre a soma da renda de todos os indivíduos residentes em um domicílio e o número total desses indivíduos. No mapa de renda per capita dos bairros de Itacoatiara, foi identificado uma diferença de rendimento significativo, principalmente ao norte da cidade, como Mamoud Amed, São Francisco e Eduardo Braga I (até 164,41 R\$); ao leste os bairros foram Da Paz e Eduardo Braga II (até 164,41 R\$). Os segundos bairros com menor rendimento estão localizados no centro, como Prainha, São Cristóvão e Santo Antônio. Do Iracy (oeste) e Centro (sul) apresentaram maior rendimento (entre 657,65 e $823 \quad$ R\$). 


\section{ESPACIALIZAÇÃO DA DENGUE: INDICADORES SOCIOESPACIAIS E ASPECTOS CLIMÁTICOS NO PROCESSO SAÚDE-DOENÇA}

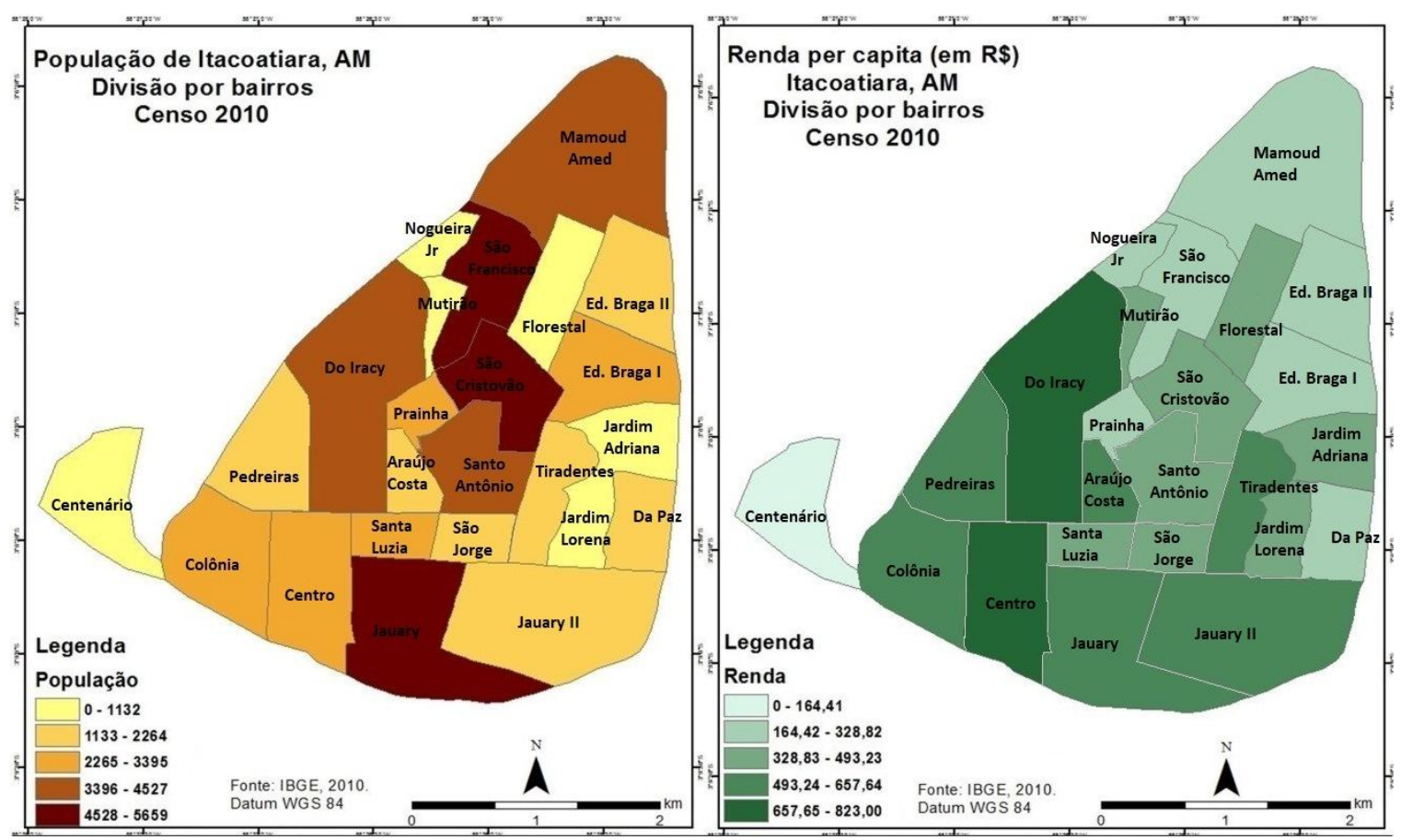

Figura 9: Mapeamento do total de habitantes por bairro e o total de renda per capita (R\$) por bairros de Itacoatiara. Fonte: Censo do IBGE, 2010.

Com base no mapa de população e renda per capita, foi identificado que os bairros com maior rendimento não corresponderam aos bairros mais populosos, por exemplo, São Cristóvão e São Francisco tiveram renda de até 164,41 em $\mathrm{R}$ e ambos são os mais populosos juntamente com Jauary $(4.528$ e 5.659 habitantes). O bairro Mamoud Amed, segundo maior populoso também teve rendimento inferior (164,41 em R\$) comparado aos bairros Do Iracy com população entre 3.396 e 4.527 habitantes, e Centro com população entre 2.265 e 3.395 habitantes, ambos com maior rendimento, 657,65 a 823,00 em Reais ( $R \$$ ).

$O$ indicador da renda foi utilizado principalmente pela relação com a saúde. O tipo de estrutura domiciliar reflete no quanto a família tem de rendimento, assim como a localização do domicilio, se está em áreas de riscos ou em solo urbano mais valorizado. Os indicadores socioespaciais (especificamente, o saneamento básico, renda e densidade populacional) apresentados neste estudo apontam fragilidades da parte do serviço público, que associados ao tipo de infraestrutura construída em solo de baixo valor (domicílios com saneamento básico precário) conduzem à formação de áreas vulneráveis ao risco de dengue.

Em relação à espacialização dos casos confirmados de dengue, tanto no ano de 2014 e 2015, ocorreram principalmente em bairros populosos e de baixa renda, como em Jauary, Jauary II, Santo Antônio, São Francisco, Mamoud Amed e São Cristóvão, respectivamente.

\section{CONSIDERAÇÕES FINAIS}

Através da condição dos sistemas de serviços de saneamento básico e variação dos elementos climáticos (pluviosidade, temperatura do ar e umidade) foi possível identificar os condicionantes na formação de áreas vulneráveis ao risco de dengue. As ocorrências de dengue predominaram principalmente nos bairros Jauary, Jauary II, Santo Antônio, São Francisco, Mamoud Amed e São Cristóvão. A abordagem sistêmica de Monteiro permitiu abordar os elementos do clima como condicionante no desenvolvimento do vetor, no qual o total de chuva menos de $80 \mathrm{~mm}$, temperaturas entre 24 a 


\section{ESPACIALIZAÇÃO DA DENGUE: INDICADORES SOCIOESPACIAIS E ASPECTOS CLIMÁTICOS NO PROCESSO SAÚDE-DOENÇA}

$35^{\circ} \mathrm{C}$ e umidade entre 70 a $80 \%$ são favoráveis ao desenvolvimento do vetor.

A abordagem socioambiental de Mendonça permitiu uma análise espacial dos indicadores de saneamento básico e da dengue nos anos de 2010, 2014 e 2015, os riscos e as vulnerabilidades socioambientais urbanos partindo da precariedade do saneamento básico (especificamente o abastecimento de água, coleta lixo e esgoto sanitário) conduziram à identificação do padrão socioespacial mais vulnerável ao risco da doença, bem como a formação de áreas vulneráveis à produção, ovulação e espacialização do vetor da dengue, no município de Itacoatiara. A articulação destes indicadores com o clima urbano da cidade permite conhecer a particularidade de cada sítio urbano, as atividades humanas, a concretude do espaço estabelecido e a qualidade de vida a ele integrada.

\section{AGRADECIMENTOS}

As autoras agradecem a FAPEAM (Fundação de Amparo à Pesquisa do Estado do Amazonas) pelo financiamento no projeto de pesquisa .

\section{REFERÊNCIAS}

AQUINO JUNIOR, J. A dengue na área urbana contínua de Maringá (PR): uma abordagem socioambiental da epidemia de 2006-2007. 15 de abril de 2010. Dissertação de Mestrado em Geografia - Setor de Ciências da Terra, UFPR, Curitiba.

AYOADE, J.O. Introdução à climatologia para os trópicos. São Paulo: Editora Difel. 2002.

BRITO, A. A. Dengue em Recife, Pernambuco: padrões clínicos, epidemiológicos, laboratoriais e fatores de risco associados à forma grave da doença. 2007. Tese de Doutorado em Saúde Pública - Centro de Pesquisas Aggeu Magalhães, FIOCRUS, Recife.
CONFALONIERI, U. E. C. Variabilidade climática, vulnerabilidade social e saúde no Brasil. In: Revista Terra Livre, São Paulo, v. 1, n. 20, p. 1932004, 2003.

COSTA, R. C. Do lugar à totalidade: metabolismo urbano, previsão de impactos e planejamento. In: FREITAS, C. M., GIATTI, L. L. (Org.). Sustentabilidade, ambiente e saúde na cidade de Manaus. Manaus: Editora Fiocruz, 2015. 3, p. 73-89.

Fundação Oswaldo Cruz. FIOCRUZ. Sobre o vírus da dengue. Disponível em: <http://www.ioc.fiocruz.br/dengue/textos/sobre ovirus.html.>. Acessado em: 13. 01. 2017.

FOREST GIS. Classificação climática de Köppen. Disponível em: <http://www.forestgis.com/2013/02/classificacao-climatica-dekoppen.html.>. Acessado em: 09.01.2017.

Instituto Brasileiro de Geografia e Estatística. IBGE. Disponível em: <http://www.biblioteca.ibge.gov.br/visualizacao/ dtbs/amazonas/itacoatiara.pdf.> Acessado em: 14.01.2017.

Instituto Nacional de Meteorologia. INMET. Disponível em: <http://www.inmet.gov.br/projetos/rede/pesqui sa/gera_serie_txt.php?\&mRelEstacao $=82336 \& b t$ $\mathrm{nProcesso}=$ serie $\& \mathrm{mRe}$ Dt Inicio $=01 / 01 / 1971 \& \mathrm{mR}$ elDtFim $=30 / 06 / 2015 \& m A$ tributos=1.>. Acessado em: 14.01.2017.

KOPPEN, W. Classificação climática de KöppenGeiger. $1901 . \quad$ Disponível em: <https://portais.ufg.br/up/68/o/Classifica___o_ Clim_tica_Koppen.pdf.>. Acesso em 11 outubro 2017.

MAGALHÃES, G. B., ZANELLA. M. E. Comportamento espacial da dengue e sua relação com o clima na região metropolitana de Fortaleza, CE, Brasil. Revista Brasileira de 


\section{ESPACIALIZAÇÃO DA DENGUE: INDICADORES SOCIOESPACIAIS E ASPECTOS CLIMÁTICOS NO PROCESSO SAÚDE-DOENÇA}

Climatologia, Fortaleza, v.12, n.1, p.114-131, 2015.

MCMICHAEL, A. J.; WOODRUFF, R. E.; HALES, S. Climate change and human health: present and future risks. Review The Lancet, v.367, n.11, p. 859-870, 2006.

MENDONÇA, F. A. Geografia Socioambiental. In: Paradigmas da Geografia. Terra Livre, São Paulo, v.1, n.16, p. 113-132, 2001.

MENDONÇA, F. A. Aquecimento global e saúde: Uma perspectiva geográfica - Notas introdutórias. In: Revista Terra Livre, São Paulo, v.1, n.20, p. 205-221, 2003.

MENDONÇA, F. A. Rechauffement global et santé: Aspects généraux et quelques particularités duMonde Tropical. Annales de l'Association Internationale de Climatologie, Liège, p.157-175, 2004.

MENDONÇA, F. A. Dengue: Dinâmica Espacial e Condicionantes Climáticos na Região Sul do Brasil. In: Efectos de los câmbios globales sobre La salud humana y La seguridad alimentaria. Programa Iberoamericano de Ciencia y Tecnologia para El Desarrollo. 2009.

Ministério da Saúde. MS. 2015. Disponível em: <http://portalsaude.saude.gov.br/images/pdf/20 15/julho/29/Dengue-at---2014.pdf>. acessado em: 14.01.2017

MONTEIRO, C. A. F. Análise Rítmica em Climatologia: problemas da atualidade climática em São Paulo e achegas para um programa de trabalho. São Paulo: IGEOG/USP, n.1, p.1-21, 1971.

MONTEIRO, C. A. F Teoria e Clima Urbano. 1976. Tese de Doutorado em Geografia. Instituto de Geografia. Universidade de São Paulo. São Paulo.

PIGNATTI, M. G. As Doenças Emergentes no Brasil. Ambiente e Sociedade. Campinas: Editora:
Scielo, 2004. Disponível em: <www.scielo.br/pdf/asoc/v7n1/23540.pdf.>. Acessado em 09.01.2017.

OLIVEIRA, M. M. F. Condicionantes Socioambientais Urbanos da Incidência da Dengue na Cidade de Londrina/PR. 2006. Dissertação de Mestrado em Geografia - Setor de Ciências da Terra, UFPR, Curitiba, 2006.

Organização Mundial de Saúde. OMS. 2014. Disponível em: <http://www.epi.uff.br/wpcontent/uploads/2013/10/Nova_classificacao_de _caso_de_dengue_OMS.pdf>. Acessado em: 13.01.2017.

PAULA, E. V. Dengue: Uma Análise climatogeográfica de sua manifestação no Estado do Paraná. 2005. Dissertação de Mestrado em Geografia - Setor de Ciências da Terra, UFPR, Curitiba, 2005.

ROUQUAYROL, M. Z. Epidemiologia em saúde $9^{\circ}$ edição. Rio de Janeiro: Editora Médica, 1999.

ROUQUAYROL, M. Z., GOLDBAUM, M. Epidemiologia, História Natural e Prevenção de Doenças. In: ROUQUAYROL, M.Z.(Org.). Epidemiologia e saúde. 4ạed. Rio de Janeiro: Editora MEDSI, 1993, p.15-30.

Sistema de Notificações e Agravos. SINAN. Dispoivel em: <http://tabnet.datasus.gov.br/cgi/deftohtm.exe? sinannet/cnv/dengueam.def $>$. acessado em: 10.01.2017.

SORRE, M. A adaptação ao meio climático e biossocial - geografia psicológica. In: MEGALE, J. F. (Org.) Max. Sorre: Geografia. São Paulo: Editora Ática S. A., 1984. 1, p. 30-86.

SOUSA, R. R. A propósito de um mapeamento da epidemia de dengue na cidade de Cuiabá, MT. Revista Geografia Acadêmica, Goiânia, v.2, n.1, p. 73-87, 2008. 